\title{
The Impact of Cooperative Learning in Comparison to Traditional Learning (Small Groups) on EFL Learners' Outcomes When Learning English as a Foreign Language
}

\author{
Rashed Alghamdi ${ }^{1}$ \& Robyn Gillies ${ }^{1}$ \\ ${ }^{1}$ School of Education, The University of Queensland, Brisbane, Australia \\ Correspondence: Rashed Alghamdi, School of Education, The University of Queensland, Brisbane, Australia. \\ E-mail: rz000@hotmail.com
}

Received: June 5, 2013 Accepted: July 11, 2013 Online Published: September 29, 2013

doi:10.5539/ass.v9n13p19 URL: http://dx.doi.org/10.5539/ass.v9n13p19

\begin{abstract}
To identify the effect of cooperative learning (CL) on the achievement's of EFL learners, a 12-week study was conducted in four secondary schools in Saudi Arabia. This study aims to examine the effectiveness of cooperative learning (CL) in developing English as a Foreign Language (EFL) students' grammatical competence in a relatively under-researched context (i.e., Arabia). In particular, this this study aims to investigate the impact of cooperative learning in comparison to traditional instruction in learning English grammar on the achievement of students. This study contributed to the knowledge about how students learn English grammar as a foreign language when they work cooperatively together in cooperative learning groups in comparison to peers who work in traditional classrooms (small groups). The participants in this study were 139 tenth grade male students, aged 14-15 years, in four boys' secondary schools in Al-Baha city.

The results showed that there are statistically significant differences between the mean scores of the students who were taught English in the cooperative learning environment (the experimental group), and those who were taught the English by using the traditional small group method (the control group) in the post-test. This difference was in favour of the experimental group. However, the results showed that are not statistically significant differences between the students in the experimental classes and the students in the control groups in their English achievement test score at the pre-test.
\end{abstract}

Keywords: applied linguistic, teaching English as foreign language, cooperative learning, and small groups processes

\section{Introduction}

Research on cooperative learning over the past three decades has documented academic and social benefits that students derive when they work together (Gillies, 2011; Gillies \& Boyle, 2011; Johnson \& Johnson, 2003, 2007; Sharan, 1994; Slavin, 1995). When students work together in small groups to achieve shared goals it is called cooperative learning.

Previous research has shown that when cooperative learning is compared to individual learning, students who learn cooperatively obtain better academic results. Similarly, when it is compared to lecture directed learning, students also obtain better academic results (Johnson \& Johnson, 2002). The other benefits of cooperative learning include enhanced thinking skills, more self-motivation to learn, higher self-esteem, greater respect for others and improved attitudes towards learning (Slavin, 1995). Cooperative learning helps enhance thinking, acquisition of information, communication and interpersonal skills, and most importantly, self-confidence (Johnson \& Johnson, 1994). These skills and characteristics are developed by dividing students into groups and then allotting them structured cooperative tasks where students work together on homework assignments, laboratory experiments or design projects.

\section{Background}

Research on cooperative learning has been extensive. For example, Slavin (1991) reviewed 70 studies that used cooperative learning techniques for more than four weeks in secondary and elementary schools and found that $61 \%$ of the studies showed that students obtained better results when they learned cooperatively than their 
control group peers. Furthermore, Slavin (1995) reviewed a further 99 studies and found that only 5\% among these studies extensively support control group gains, while $63 \%$ among these studies appreciably support cooperative learning.

In the context of EFL, such as in Taiwan, it has been verified by many researchers that social relations can be improved, motivation can be increased, and goals can be achieved under cooperative learning (Chang, 1995; Chu, 1996; Lo, 1998; Wei, 1996; Yu, 1993). This contention has been demonstrated empirically by three major studies of current time by Chen (1998), Chen (1999) and Liang (2002). Liang's study is rigorous, since various methods have been used in collection and analysis of data such as content analysis, testing, interviewing, observations and questionnaire surveys.

In addition, other studies that were conducted in Taiwan (Kao, 2003; Liao, 2005) showed that motivation and speaking skills can be enhanced via cooperative learning. These studies were conducted on junior and senior high students in Taiwan regarding their cooperative learning and its effects on their learning motivation and English speaking skills.

With regards to the Vietnamese context, Dang (2007), Pham (2010), Tuan (2010), conducted various studies on cooperative learning among students of secondary and intermediate level where they analysed the experiences and perceptions of students. The results showed that language skills were improved, interpersonal skills were developed and creative thinking was promoted upon undertaking cooperative learning. However, not all studies are supportive of CL. Bock (2000) conducted studies on cooperative learning pedagogy in Vietnamese EFL classrooms at a tertiary level and found that students were unwilling to cooperate with the teachers. In Turkey, Mohammad (2010) examined the implementation of cooperative learning groups to understand the effect on learning achievements and attitudes in college mathematics in the context of virtual online grouping coupled with in-class grouping. The study revealed that the students' mathematics achievement and attitudes toward mathematics improved as a result of cooperative grouping.

In Saudi Arabia, there are a few studies that have been conducted in cooperative learning (Alharbi, 2008; Alghamdi, 2013; Algarfi, 2010). Alharbi (2008) conducted a study on the effect of using cooperative learning on EFL reading comprehension performance and attitudes of students toward cooperative learning and students' motivation toward reading at a girls' school. The participants were 60 students from three secondary schools. A quasi-experimental design was used in this study. There were two groups, a control group of 30 students and an experimental group of 30 students. The result of this study revealed that there was no significant difference between the two groups in terms of students' motivation toward reading. However, the results showed that there was significant difference between the experimental group and control group in terms of reading comprehension performance and students' attitudes toward cooperative learning in favour of the experimental group.

There have been a few studies to measure the impact of cooperative learning on students' achievement of English grammar such as Liao (2005). Liao's study examined the impact of cooperative learning on motivation, learning strategy utilization and grammar achievement of English foreign language learners in Taiwan. A quasi-experimental comparison group study for three months was designed. Forty-two students of two college classes participated in the study. Learners' pre-test and post-test scores were used to collect data. The result revealed that cooperative learning had large positive effects on motivation and English grammar achievement.

\section{Research Questions}

1) What is the effect of cooperative learning in comparison to traditional small group learning on the achievement of EFL learners?

2) What is the effect of cooperative learning in comparison to traditional small group learning on the achievement of grammatical knowledge of EFL learners?

3) What is the effect of cooperative learning in comparison to traditional small group learning on the achievement of writing skills of EFL learners?

\section{Methodology}

\subsection{Intervention}

The researcher organized a workshop: for teachers of the experimental groups who trained in cooperative learning skills. In this study, the researcher-compared cooperative learning groups and small groups who were not trained in cooperative learning skills.

\subsection{Cooperative Learning Groups (Training Program)}

The researcher organized a workshop for five weeks to train both the teachers and the students in the 
experimental condition in the basic skills of cooperative learning. Johnson and Johnson (1999) maintain that teachers have to be familiar with the basic skills to implement cooperative learning properly. For example, the teacher should be able to form cooperative groups, monitor the process and outcomes of the group experience, and explain the expectations for the group as well as individual members. The researcher invited the teachers to attend the workshop to clarify the basic skills that needed to be developed to ensure that the cooperative learning intervention was correctly implemented.

A cooperative learning intervention-training program developed by Gillies and Ashman (1995) Gillies (2003, 2007) was modified and used by the researcher to train the teachers who taught the experimental groups in this study (see appendix for full program...). Johnson and Johnson (2003) pointed out that the use of cooperative training program assists group members to be more proficient in providing learning experiences. Particular benefits to group training include: The group members are able to explain new experiences to each other, Group feedback, Motivation that enhances group members, Encouragement to learn, professional Development identity. The use of training assists group members to become more proficient in implementing learning experiences (Johnson \& Johnson, 2003). An overview of the intervention-training program is outlined below:

1) Discussion of CL five principals: positive interdependence, small group skills, and group processing, face-to-face interaction and individual accountability. These are basic skills of cooperative learning method, students have trained to use them otherwise they cannot work cooperatively in groups.

2) "We instead of me" positive interdependence. It exists when group members are linked together in such a way that one cannot succeed unless others do also (Gillies, 2007).

3) "No hitchhiking on the work of others" individual accountability. Every student in the group should identify his role and he has to do it. Individual accountability exists when each group member understands that they are responsible for completing the assigned tasks and assisting others to complete their assigned tasks as well (Holliday, 2005) .It means students have different activities in one group.

4) Understanding group social skills: students need to be familiar with social skills such as listening politely, disagreeing and taking turns to work in groups properly.

5) Sharing of experiences: what were the benefits of CL? What were the disadvantages? How could the approach be sustained? And video clips about cooperative learning.

The cooperative learning intervention program had many benefits for the teachers participating in the group training. These included opportunities to: receive group feedback, provide encouragement to learn, clarify new experiences with colleagues, enhance personal commitment, and validate professional identity.

Jacob (2002) mentioned several principles that teachers should be aware of when they decide to implement cooperative learning in their classrooms: teachers should understand the definition of cooperative learning, its principles and they should be able to arrange and manage their classroom. Furthermore, they should be able to build teams and construct groups and they should be able to assist different groups to develop independence by delegating responsibility for learning.

The researcher introduced the training program. The role of the researcher was as follows: He prepared PowerPoint slides on cooperative learning method, handouts; translated some difficult sentence from English to Arabic, answered teachers' questions and chose a good room in one school where the teachers attend the program. During the meeting, the researcher introduced himself and he started with a brief introduction about the project. The researcher clarified the following issues: the importance and purpose of the research; the definition of cooperative learning and its principles as discussed in chapter 2 (positive interdependence, individual accountability, group processing, face to face interaction and social skills), the need for cooperative learning in Saudi Arabia schools, building a cooperative team; how to embed cooperative learning into classroom lessons; and the role of the teacher in cooperative learning.

In addition, the teachers watched a video (DVD) in the training program which is called "pedagogy and practice: teaching and learning in secondary schools (DFES, 2004). This video consists of many clips that clarify the use of cooperative learning in the classroom. These clips clarified what a cooperative learning classroom might look like, the teacher's role in implementing cooperative learning in the classrooms and the student's tasks. They also watched another two video clips by Spencer Kagan (2010), the first one is titled "What is cooperative learning" and the second one is called "Differences between CL and small groups"

The researcher also introduced three books on cooperative learning for the teachers to read. These books are Cooperative learning integrating theory and practice by Gillies (2007); the teacher's sourcebook for cooperative learning: practical techniques, basic principles and frequently asked questions by Jacobs, Power and Loh (2002); 
and Learning together and alone: cooperative, competitive, and individualistic learning by Johnson and Johnson (1991). These three books were useful for the teachers as they assisted them to improve their management of the classroom, giving clear ideas on using cooperative learning and implementing it in the classroom effectively.

Following the workshop, the researcher asked the teachers to train their students in the basic skills of cooperative learning before beginning the first class. The researcher assisted the teachers to instruct the students in social skills for group work. The workshop included working together to develop group goals, correcting classmate's mistakes, using quiet signals, sharing information, proposing good arguments and cooperation.

During the study, the students in the experimental groups were taught English using cooperative learning whereas the control groups were taught English using the traditional method (small groups). All groups were taught the same subject matter and used the same content. All groups received the same amount of time for instruction.

\subsection{The Schools}

The four schools selected for the research have a similar socio-demographic profile and the student population of each school range from 180 to 200 students. All students are from a similar middle-class socio-economic Saudi background. All selected schools are ranked with an excellent grade by the Ministry of Education in Saudi Arabia. The Ministry of Education evaluates the general schools every year depending on specific criteria such as students' achievement, teachers' performance and school activities. There are many supervisors who are responsible for visiting schools regularly. In so doing, they evaluate each school using the criteria that were designed by the Ministry of Education in Saudi Arabia.

\subsection{Teachers}

Four male English teachers from the four schools were invited to participate in the research. All teachers have bachelor degrees in teaching English with similar experiences at teaching English. Furthermore, they have obtained a teacher performance rating of $90 \%$ or more. This is a rating in teacher performance that is usually undertaken every year by Ministry of Education and is a measure of teachers' competence (ability). The teachers who were invited to participate in the research are competent and all had opportunities to participate in the training for the different conditions.

\subsection{Participants and Sampling}

The participants in this study were 139 10th-grade male students, aged 14-15 years in four boys' secondary schools in Al-Baha city. Four English teachers located in 4 secondary schools were invited to participate in the study. Schools were randomly assigned to one of two conditions: Four 10th-grade classes were randomly selected from two schools to form the experimental groups and four classes were randomly selected from another two schools as control groups. All schools are government boy's schools located in Al-Baha city. There were 70 students in the experimental conditions and 69 students in the control conditions. There were four students in each group and the students in the groups were sub-sets of the sample who took the pretest, post-test (see Table 1):

Table 1. Research design

\begin{tabular}{llllll}
\hline Number & Condition & Learning method & Classes & Groups & Teacher \\
\hline School 1 & Experimental & CL & A, B & $1,2,3,4$ & 1 \\
School 2 & Experimental & CL & C, D & $5,6,7,8$ & 2 \\
School 3 & Control & Small groups & E, F & $9,10,11,12$ & 3 \\
School 4 & Control & Small groups & G, H & $13,14,15,16$ & 4 \\
\hline
\end{tabular}

\subsection{Instrument and Data Collection}

The researcher collected quantitative data in this study. The instrument that was used to collect data is a pre-test and post-test English grammar achievement test. The instrument is discussed below.

\subsection{English Grammar Achievement Test}

The test was used as both a pre-test and a post-test to investigate the impact of the cooperative learning method on students' English language achievements. The test is comprised of twenty multiple-choice questions. At the 
beginning of the test, the participants were asked to choose the correct answer from four options and the time allocated for this part was 40 minutes. After that, the students were required to write a paragraph to identify their productive grammar and the time allocated for this part was 20 minutes. The time allocated for the whole test was 60 minutes. There were two marks for each correct answer in the multiple-choice question and ten marks for the writing task, making the total score obtainable at fifty.

The participants' previous achievements in English were evaluated by the pre-test distributed to both conditions (experimental \& control) before the study began. The purpose of the pre-test was to assess the students' background knowledge of grammar, particularly of present simple, past simple and future simple tenses. The same pre-test was presented at the end of the study as a post-test to evaluate the participants' achievements on the English grammar achievement test. The purpose of the post-test was to assess the impact of both the traditional learning method and cooperative learning method on students' achievements. Two English teachers who did not participate in this study corrected all the English test papers. They corrected the test papers both at the beginning of the study and at the end of the study. With the writing task, they corrected each paragraph twice separately and then calculated the average mark between them. A total of 139 participants relatively evenly drawn from four government secondary schools and eight classrooms experienced either the experimental condition, $(\mathrm{N}=70)$ or the control condition $(\mathrm{N}=69)$.

\section{Results and Analysis}

In order to determine if there were differences in the students' achievement scores in grammar in the two conditions, an Analysis of Variance (ANOVA) was performed. Because the English grammar achievement test has two parts, a multiple-choice and writing task, the researcher analysed it in two ways: firstly, presenting and discussing the results of it totally (multiple choice + writing task); and secondly, analyzing the two parts of it separately (multiple-choice and writing task). The means and standard deviation of the English grammar achievement pre-test total score and post-test total are displayed in the following Table 2:

Table 2. Means and standard deviation in the total of pre-test and total of post-test scores for the experimental and control conditions

\begin{tabular}{|c|c|c|c|c|}
\hline & & $\mathrm{N}$ & $\mathrm{M}$ & SD \\
\hline \multirow{3}{*}{ re-test total scores } & Experimental & 70 & 16.83 & 5.858 \\
\hline & Control & 69 & 15.91 & 5.207 \\
\hline & Total & 139 & 16.37 & 5.543 \\
\hline \multirow{3}{*}{$\begin{array}{l}\text { Post-test } \\
\text { scores }\end{array}$} & Experimental & 70 & 19.17 & 6.258 \\
\hline & ${ }^{\mathrm{al}}$ Control & 69 & 16.72 & 4.537 \\
\hline & Total & 139 & 17.96 & 5.588 \\
\hline
\end{tabular}

In order to determine if there were differences between both the pre-test and post -test total score results, two one-way ANOVAs were conducted. As can be seen in Table 2, there were no significant differences between the experimental and control conditions at Table 1 but there were significant differences at Table 2.

Table 3. Tests of between subject effects for pre-test and post-test total scores

\begin{tabular}{lllllll}
\hline ANOVA & & SS & df & MS & F & Sig. \\
\hline Pre-test total scores & Between Groups & 29.126 & 1 & 29.126 & 0.947 & 0.332 \\
& Within Groups & 4211.421 & 137 & 30.740 & & \\
& Total & 4240.547 & 138 & & & \\
Post-test total scores & Between Groups & 208.030 & 1 & 208.030 & 6.948 & 0.009 \\
& Within Groups & 4101.711 & 137 & 29.939 & & \\
& Total & 4309.741 & 138 & & & \\
\hline
\end{tabular}

Table 3 indicates that there are no statistically significant differences, $p=0.332(p>0.05)$ between the mean 
scores of the students who were taught English in the cooperative learning environment (the experimental group) and those who were taught English by using the traditional method (the control group) in the pre-test.

In contrast, Table 3 shows that there are statistically significant differences, $p=0.009(p<0.05)$ between the mean scores of the students who were taught English in the cooperative learning environment (the experimental group) and those who were taught English by using the traditional method (the control group) in the post-test in favor of the experimental conditions.

To determine if there were differences between the conditions on the multiple choice questions and the writing task from Table 1 to Table 2, two Analyses of Covariance (ANCOVA) were conducted. The following table (4) presents the means and standard deviations of the students' scores on the multiple-choice test and the writing test separately at Tables 1 and 2 .

Table 4. The means and standard deviations of the students' scores on the multiple-choice test and the writing test at pre test and post test

\begin{tabular}{llll}
\hline Condition & $\mathrm{N}$ & $\mathrm{M}$ & $\mathrm{SD}$ \\
\hline Multiple-choice (1) Experimental Control & 70 & 15.12 & 4.85 \\
& 69 & 14.59 & 4.30 \\
Multiple-choice (2) Experimental Control & 70 & 16.91 & 5.10 \\
& 69 & 15.17 & 3.67 \\
Writing task (1) Experimental Control & 70 & 1.70 & 1.42 \\
& 69 & 1.31 & 1.20 \\
Writing task (2) Experimental Control & 70 & 2.25 & 1.48 \\
& 69 & 1.55 & 1.24 \\
\hline
\end{tabular}

NB. Maximum score for the multiple test $=40$; Maximum score for the writing task $=10$; Maximum Total score $=50$.

To determine if there were significance differences between the conditions on the multiple-choice questions and the writing task from Table 1 to Table 2, two Analyses of Covariance (ANCOVA) were conducted. As can be seen in Table 4, there were significant differences in the multiple-choice question in favor of the experimental condition. However, there were no significant differences in the writing task question between the experimental and control conditions. The results are shown in the following Table 5:

Table 5. Tests of between subject effects for two difference scores (post-test minus pre-test)

\begin{tabular}{lllllll}
\hline DV & Type III SS & df1 & df2 & MS & F & Sig. \\
\hline Multiple- choice & 50.54 & 1 & 137 & 50.539 & 7.688 & 0.006 \\
Writing task & 3.68 & 1 & 137 & 3.676 & 2.685 & 0.104 \\
\hline
\end{tabular}

As indicated in Table (5), condition predicted significantly larger differences in scores for multiple-choice question responses, $p=0.006(p<.05)$. In contrast, there were no significant differences in scores with the writing task, $p=0.104(p>$.05). (See appendix number (3) for statistics details). As illustrated in Figure 1 and 2, outcome scores were on average larger in the experimental condition for both outcome variables whether considered separately or in terms of total scores. However, when considered in relation to the error bars, outcomes for multiple choice questions at post-test, for writing task questions at post-test, and for total scores at post-test were more clearly different and not over lapping. 


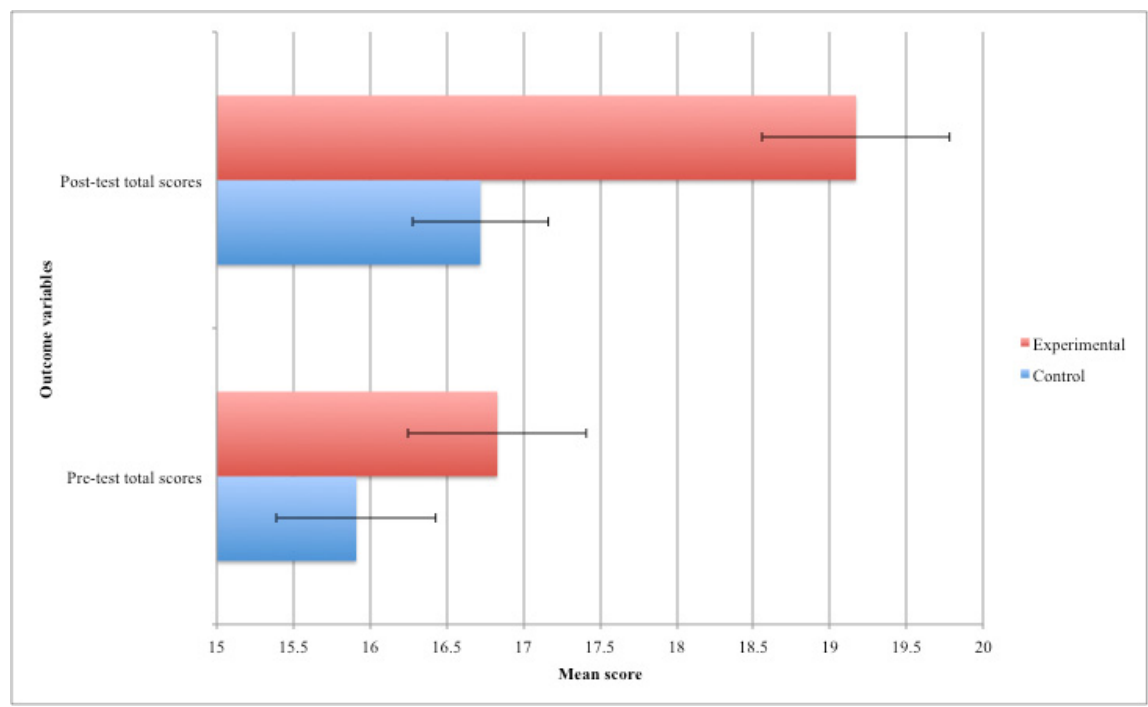

Figure 1. Test outcome scores by condition (standard error bars visible)

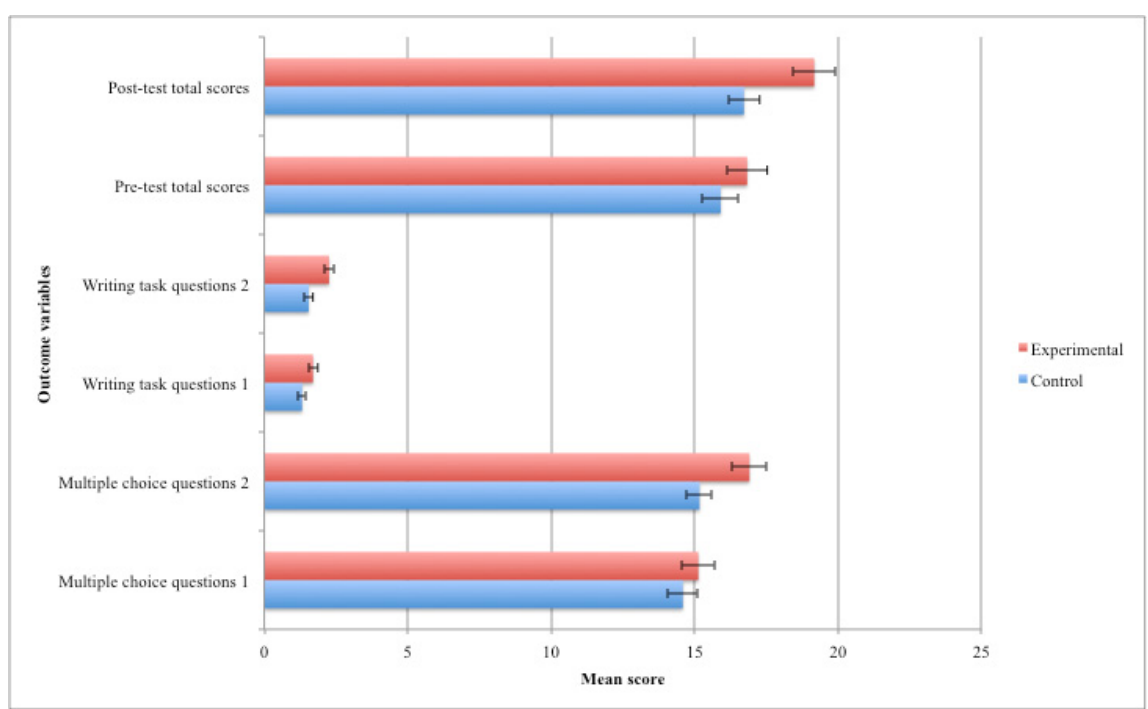

Figure 2. Test outcome scores by condition (standard error bars visible)

\section{Discussion}

The results showed that there are statistically significant differences, $p=0.009(p<0.05)$ between the mean scores of the students who were taught English in the cooperative learning environment (the experimental group), and those who were taught the English by using the traditional small group method (the control group) in the post-test. This difference was in favour of the experimental group. However, the results showed that there are no statistically significant differences between the students in the experimental classes and the students in the control conditions in their English achievement test score at the pre-test. This finding demonstrates that the students had the same background knowledge of the grammar items before the implementing of the cooperative learning method, confirming that any gain in the students' achievements could be attributed to the cooperative learning environment.

There are two possible explanations for increase in students' achievement when they worked cooperatively. Firstly, learning English through cooperative learning enables students to work in groups and discuss many tasks (Gillies, 2007). Secondly, weak students in each group learn from more able students rather than their teacher (Johnson \& Johnson, 2003). The researchers in the cooperative learning field believe that students can learn more efficiently through cooperative learning environment (Johnson \& Johnson, 2003). The results obtained were consistent with the results of many previous studies. For example, Liao (2005) examined the impact of 
cooperative learning on motivation, learning strategy utilisation and grammar achievement of English foreign language students in Taiwan. A quasi-experimental comparison group study for three months was designed. Forty-two students of two college classes participated in the study. Learners' pre-test and post-test scores were used to collect data. The result revealed that cooperative learning had large positive effects on motivation and English grammar achievement.

Kao (2003) and Liao (2005) showed that motivation and speaking skills can be enhanced via cooperative learning. Dang (2007), Tuan (2010) and Vo (2010) also conducted various studies on the effectiveness of cooperative learning on the achievements of students in secondary and intermediate levels. The results showed that language skills and students' achievements were improved, interpersonal skills were developed and creative thinking was promoted upon undertaking cooperative learning.

Other studies such as Gillies (2010, 2011), Kao (2003) and Liao (2005) concluded that cooperative learning increased student's achievements. However, in this study the researcher videotaped eight classes in four secondary schools to identify why cooperative learning increases the students' achievements and the reasons that enabled students who learn English via cooperative learning to obtain higher scores on their English achievement test.

\section{Conclusion}

In a summary, to identify the impact of cooperative learning (CL) on acheivments of EFL learners, a study was conducted in four secondary schools in EFL classrooms environment. The data pointed out that there was a significant difference between the two conditions (experimental, control). The results showed that there are statistically significant differences between the mean scores of the students who were taught English in the cooperative learning environment (the experimental group), and those who were taught the English by using the traditional small group method (the control group) in the post-test in favor for the experimental conditions.

\section{References}

Algarfi, A. (2010). Teachers and pupils perceptions of and responses to cooperative learning methods within the Islamic culture courses in one secondary school in Saudi Arabia. Ph.D thesis, University of Southampton, Faculty of Law, Arts \& Social Science School of Education, Southampton.

Alghamdi, R. Z. (In press) (n. d.). EFL learners' verbal interaction during cooperative learning and traditional learning small groups. Journal of Language Teaching and Research, 5(1).

Alhaidari, M. S. (2006). The effectiveness of using cooperative learning to promote reading comprehension, vocabulary, and fluency achievement scores of male fourth-and fifth-grade students in a Saudi Arabian school. Ph.D thesis, the Pennsylvania State University.

Alharbi, L. A. (2008). The effectiveness of using cooperative learning method on ESL reading comprehension performance, students' attitudes toward CL, and students' motivation toward reading of secondary stage in Saudi public girls' schools. Ph.D thesis, West Virginia University.

Bock, G. (2000). Difficulties in implementing communicative theory in Vietnam. Teachers' Edition, 2, 24-30.

Chu, M. (1996). An application of the Jigsaw method in a freshman English class. Hwang-Kung Foreign Languages Journal, 207-222.

Dang, T. P. H. (2007). Implementing cooperative learning in foreign language classes. Journal of Science and Technology, 15, 1-5.

Gillies, R. M. (2007). Cooperative learning: integrating theory and practice. Thousand Oaks, CA: SAGE Publications.

Gillies, R. M. (2011). Promoting thinking, problem-solving and reasoning during small group discussions. $\begin{array}{lllll}\text { Teachers and Teaching: Theory and Practice, } & \text { 17(1), }\end{array}$ http://dx.doi.org/10.1080/13540602.2011.538498

Gillies, R. M., \& Ashman, A. F. (1995). Promoting Cooperative and Helping Behaviours in Student Work Groups through Training in Small Group Processes, 7.

Gillies, R. M., \& Ashman, A. F. (2000). The Effects of Cooperative Learning on Students with Learning Difficulties in the Lower Elementary School. Journal of Special Education, 34(1), 19-27. http://dx.doi.org/10.1177/002246690003400102

Gillies, R. M., \& Boyle, M. (2005). Teachers' Scaffolding Behaviours During Cooperative Learning. Asia-Pacific Journal of Teacher Education, 33(3), 243-259. http://dx.doi.org/10.1080/13598660500286242 
Gillies, R. M., \& Boyle, M. (2008). Teachers' discourse during cooperative learning and their perceptions of this pedagogical practice. Teaching and Teacher Education, 24(5), 1333-1348. http://dx.doi.org/10.1016/j.tate.2007.10.003

Holliday, D. C. (2005). Cooperate and feel great: Cooperative learning training manual. Lanham: University Press of America.

Johnson, D. W., \& Johnson, R. T. (1999). Learning together and alone: cooperative, competitive, and individualistic learning. Boston: Allyn and Bacon.

Johnson, D. W., \& Johnson, R. T. (2002). Learning Together and Alone: Overview and Meta, Äêanalysis. Asia Pacific Journal of Education, 22(1), 95-105. http://dx.doi.org/10.1080/0218879020220110

Johnson, D. W., \& Johnson, R. T. (2004). Implementing the Teaching Students To Be Peacemakers Program. Theory Into Practice, 43(41), 68-79.

Johnson, D. W., \& Johnson, R. T. (2008). Social Interdependence Theory and Cooperative Learning: The Teacher's Role, 9-37. Boston, MA: Springer US.

Kao, E. S. (2003). The effectiveness of small-group discussion on the improvement of EFL learners'reading ability in large. Taipei,Taiwan:Tamkang University Press.

Liao, H. C. (2005). Effects of cooperative learning on motivation, learning strategy utilization, and grammar achievement of English language learners in Taiwan. Dissertation/Thesis.

Lo, Y. H. (1998). Cooperative learning: Materials and methods for a two-year junior college English class.

Muhammad, Z. (2010). Effects of cooperative learning intervention on mathematics achievement outcomes and attitudes of non-science college majors. Dissertation/Thesis. Retrieved from http://uq.summon.serialssolutions.com/link/

Pham, T., Gillies, R., \& Renshaw, P. (2010). Cooperative Learning (CL) and Academic Achievement of Asian Students: A True Story. The University of Queensland, St Lucia, QLD 4072, Australia.

Sharan, S. (1994). Handbook of cooperative learning methods. Westport, Conn: Praeger.

Slavin, R. E. (1991). Synthesis of research on cooperative learning. Educational leadership, 48(5),71-82.

Slavin, R. E. (1995). Cooperative learning: Theory, research, and practice (2nd ed.). Needham Heights, MS: Allyn and Bacon.

Tuan, L. T. (2010). Infusing cooperative learning into an EFL classroom. English Language Teaching, 3(2), 64.

Vo, T. K. A. (2010). Is cooperative learning a suitable teaching and learning method in Vietnam? Journal of Science and Technology, 6(41), 207-210.

Wei, C. L. (1996). Cooperative English learning activities: Perceptions of Taiwanese college students. Educational Research, 4, 13-26.

\section{Copyrights}

Copyright for this article is retained by the author(s), with first publication rights granted to the journal.

This is an open-access article distributed under the terms and conditions of the Creative Commons Attribution license (http://creativecommons.org/licenses/by/3.0/). 